\title{
X線と中性子をプローブとした結晶性ポリプロピレンの 外場下での変形挙動の研究
}

\author{
住友化学株石油化学品研究所 野末佳伸
}

\begin{abstract}
Yoshinobu NOZUE: Deformation Behavior of Isotactic Polypropylene Under External Force Field Investigated by X-ray and Neutron Scattering Techniques

The understanding of crystal and chain structure evolution during the processing is one of the most essential information for the design of polymer with better processability and physical properties. For this purpose, X-ray and neutron scatterings are very powerful tools. In this paper, focusing on the deformation behavior of isotactic polypropylene (iPP) under external field, we introduce 1) application of microbeam SAXS-WAXS to the observation of iPP spherulite deformation process and 2) application of SANS for clarifying the role of each molecular weight component (low, medium and high molecular weight component) on shish-kebab structure formation of iPP.
\end{abstract}

\section{1. 成形加工と結晶性高分子の変形}

\section{1 高分子の結晶構造}

人工高分子は, 結晶性という観点で結晶性高分子と非晶 性高分子に分類される. 結晶性高分子を溶融状態から過冷 却して結晶化させると, 結晶化の最初期に熱的に安定な核 を生成して, 核から三次元的に結晶が成長し, 球状の結晶 組織 (球晶と呼ばれる) を形成する。ただし, 結晶性高分子 が形成する構造は,いわゆる無機物質やタンパク質などの 結晶とは異なり, 分子のうちの一部分しか結晶化していな い. すなわち, 球晶の内部には, 結晶部分と非晶部分が存 在している. 高分子は, 一次元に長い分子鎖状の分子形態 であるので, 鎖間の絡み合いなどによって生じる分子鎖方 向の運動学的なフラストレーションがあり, 分子鎖方向に 結晶成長できるサイズは限られてしまう。 そのため, 得ら
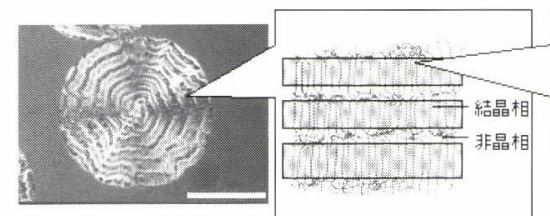

光学顕微鏡篗察

球晶の槿造

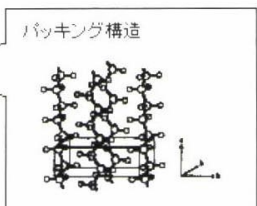
X線広角散乱法
WAXS

結晶のノヘッキング構造
図1静置場で結晶化した結晶性高分子の階層構造と, そ の観察手法. (Hierarchical structure of crystalline polymer grown under static field and their observation methods.)
れる結晶形態は板状になり，ラメラ構造と呼ばれる。 ラメ ラの結晶内部を見ると, 通常の結晶と同様に, 分子鎖が規 則正しくパッキングし, 単位格子が存在して周期構造を形 成している(図1)。ミクロンスケールの球晶は, 偏光顕微 鏡などで観察できる. ラメラの周期構造は, 結晶化温度・ 高分子種などによっても異なるが，一般的に数十一数百 程度であり，X線小角散乱 (SAXS) でその構造を観察する ことができる。ラメラ内部の結晶単位格子はX線広角散 乱 (WAXS) で観察することができる.

\section{2 結晶性高分子の流動結晶化と加熱延伸}

高分子からなるプラスチック製品は, 世の中に広く流通 しており，自動車のバンパーや内装材，包装フィルム，デ イスプレーの保護フィルムや太陽電池の封止材, 食品・洗 剂などのボトルなど, 非常に幅広い分野で使われている. これらの製品のほとんどは, 原料の高分子から所望の形に するために，成形加工が施されている．結晶性高分子の場 合の成形方法についておおまかに分類すると，(1)いった ん結晶成分を加熱・融解させ, 流動性の高い溶融状態にし てから，外場によって鋳型に流し込んだり，薄く延ばした りして所望の形にする方法, と（2）加熱によって, 結晶を 残存させつつも变形しやすい状態にしてから外場を加え て試料を引き伸ばし，所望の形にする方法に分類される。

(1)の方法で成形した場合には，溶融状態の高分子に外 場が加えられ，加工条件などによっては，シシケバブ構造 と呼ばれる, 球晶とはまったく異なる特異な構造を形成す ることが知られている. ‘シシケバブ’と言うと, 普通はト ルコ料理で有名な肉の虫焼きを連想される読者が多いかも しれないが，高分子のシシケバブは，まさに串焼きのよう 


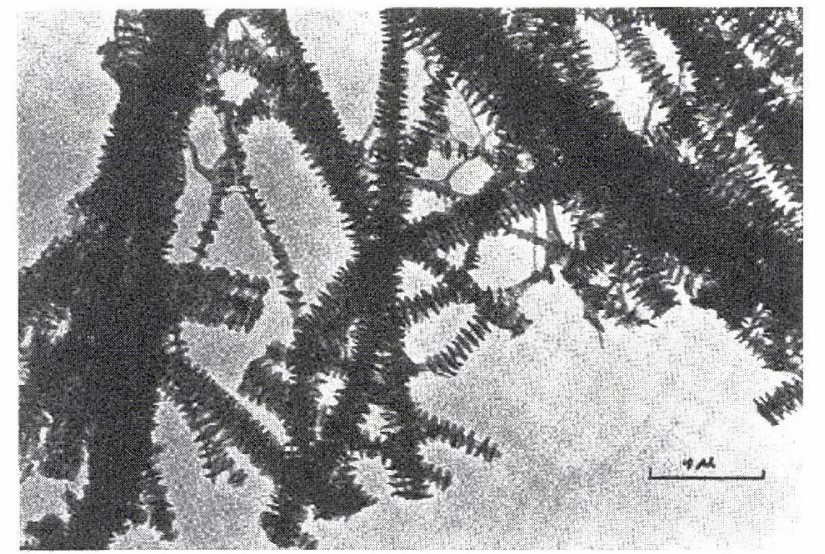

図2 Penningsらによって初めて見出されたポリエチレ ンのシシケバブ構造の TEM 写真. (TEM picture of shish-kebab structure of polyethylene which was discovered by Pennings.)

な変わった結晶形態であり, 料理からそのまま名前をとっ でシシケバブ構造’と言われている. 図 2 は, Penningsら が初めて発見した, シシケバブ構造の記念すべき電子顕微 鏡写真であり,1)シシと呼ばれる串の部分とケバブと呼ば れる串に刺さった肉の部分に対応する構造がはっきりと 観察できるかと思う。このシシケバブ構造の発見以来, シ シケバブ構造という不思議な結晶形態がどのようにして 形成するのか, シシ部分の構造は一体どうなっているの か, また, その物性はどのようなものなのか, 数多くの高 分子研究者の関心を集め, これまでに精力的に研究がなさ れてきた. しかし，その発見から 40 年以上経った今でも， シシケバブ構造の形成機構は完全には理解されていない.

一方, (2)の方法で成形する場合には, 球晶で構成され ているシートを, 結晶の融点よりも $10 \sim 30^{\circ} \mathrm{C}$ 程度低い 温度まで加熱した状態で, 逐次ないしは同時に 2 軸の延伸 を行い, 成形品を製造する。この成形法の場合, 延伸变形 の際に, 球晶を構成する結晶構造が再配列していくが, 球 晶という三次元に等方的な構造に対して例えば1軸(ない しは2軸) 方向に偏った延伸を加えると, 球晶の中でも変 形しやすい領域と変形しにくい領域が存在する。つまり, 1 つの球晶の中でも, 外場に対して变形しやすい領域に応 力集中が起こっているわけであるが,このような構造の弱 い部分への応力集中は, 球晶よりもミクロなナノスケール 構造, 例えばラメラ構造のレベルでの変形でも生じている ことが予想される. 特に, アイソタクチックポリプロピレ ン (iPP) でよく知られている, ラメラ構造がほぼ直角にク ロスして存在しているクロスハッチ構造2)や,バンド球晶 として知られている周期的にラメラが权じれた構造3に おいては, ナノスケールの領域でも非常に複䧱な心力の伝 播が生じて, 段階的に階層構造が変形していくことが予想 される。しかし, 局所での階層構造の変形過程の序列, す なわち応力伝播の序列を観察するのは非常に難しく, これ
まで報告されてこなかった．

本稿では, これらの未解決の課題を克服すべく, iPPを 用いて筆者が進めてきた研究を紹介する。前半部分では, 流動結晶化研究について, シシケバブ構造の形成機構を明 らかにすべく行ってきた中性子散乱の研究から得られた 知見 4) を, 後半部分では, 加熱延伸時に生じる iPP 球晶内 部のクロスハッチ構造の構造変形過程をマイクロビーム $\mathrm{X}$ 線小角 ·広角散乱一偏光顕微鏡同時観察し, そこから見 出した応力伝播の序列に関する知見 5) を, それらの研究の 背景も踏まえたうえで紹介していく.

\section{2. シシケバブ構造に関する研究}

\section{1 シシケバブ構造形成に関連するこれまでの研究}

\section{1 .1 シシケバブ構造の発見とその物性}

シシケバブ構造に関する研究は1960年代に遡り, 三橋6) とPenningsらりがほぼ同時に, 流動場を加えられたキシ レン溶液中のポリエチレンが, シシケバブ構造の結晶を形 成していることを発見したことに端を発する。 その後, シ シケバブ構造は, 流動する溶液のような伸長場のみなら ず, 射出成形などのようなせん断場を溶融体に印加するこ とによるせん断結晶化によっても誘起されることがわか ってきた。

さらに：シシケバブ構造を形成したポリエチレン $(\mathrm{PE})$ 成形体の物性を測定した結果, 非常に高い弾性率 (10 GPa) を示すことがわかり,7)-99 成形体は高度に配向し, 結晶化度 が高い構造を有していることがX 線構造解析などから明 らかになった. 高い弾性率をもつシシケバブ構造の魅力は 非常に大きい. 特に, PEの結晶弾性率は鉄よりも高いこと が知られており, シシケバブ構造を上手に制御して高い結 晶化度・高配向度の構造を成形体内で実現すれば, 鉄より も剛性のあるプラスチックを作れる，という大きな夢につ ながる。その一部はすでに, 超高分子量ポリエチレンによ 万超高強度繊維 (弾性率〜 $100 \mathrm{GPa}$ ) で実現されている.10)

\section{1 .2 コイルーストレッチ転移}

シシケバブ構造のシシ (串の部分) 形成に関しては, 発 見当初から, 流動場によって高分子が伸長されることが重 要であると考えられていた. 1970 年代にde Gennesは，あ る速度以上の流動場ではコイルーストレッチ転移が起こ り得ることを理論的に説明した.11)コイルーストレッチ転 移とは, ランダムコイル状態のポリマーが流動場によって 伸長した状態のほうが自由エネルギーが安定化する，とい う考えである。粘弾性体であ机ば，伸長したエントロピー が低い状態で安定化するのは一見矛盾するように思える が，いったん伸長すると，元の状態に戻るためには，伸長 した分子の周囲に新たに形成される絡みあい点の摩擦抵 抗 (ないしは, 配向した隣接分子の粘度による摩擦抵抗) を克服しなければならない. 経験的にシシケバブ構造の形 成は高分子量の成分を含むと促進される,7)という知見が 
得られてきたことから, シシケバブ構造のシシ形成には, 緩和の遅い成分がコイルーストレッチ転移することが 1つの重要な因子である, という考えが, 多くの研究者に 支持されてきた。

\subsection{3 流動誘起結晶化のその場観察と臨界絡み合い濃度}

シシケバブ構造は流動場中で形成されるため, その形成 過程をその場観察することは非常に重要である. シシケバ ブ形成過程を観察するための手段として, 複屈折や濁度, 光散乱，X線散乱などが主に用いられてきた，当初は，流 動をかけたままその結晶化の様子を観察していくという手 法が採られた。しかし, シシケバブ構造形成には, 流動に よる高分子の変形, 緩和, シシ構造の形成, ケバブ構造の 結晶化という複数の過程が存在し, 構造形成の際に, 互い にほかの過程に複雑に影響を与えあうため, 流動をかけな がら結晶化の様子を観察してもシシケバブ形成の本質を抽 出するのは非常に難しい.つまり, シシケバブ形成過程を 明確に理解するためには, 分子の変形・シシ形成などの各 過程を巧みに分離するモデル実験が必要となってくる.

Janeschitz-Krieglらは，それらを分離する方法として,ご く短時間の流動 (パルス状のせん断) を印加し, その後の 構造形成の様子を観察するという方法を見出した.12,131 彼 らは, パルス状せん断印加後の構造形成を複屈折変化で観 察し, その結果, シシケバブ構造形成の際には, 流動場に 誘起された高分子の变形によって, 針状の結晶前駆体 (thread-like precursor) が形成さ机ることが明らかになっ てきた.

関と Kornfieldらは最近, パルスせん断を印加する方法 で複屈折・濁度变化のその場観察などを行い, 非常に重要 な新しいシシケバブ構造形成の概念を提案した.14)彼らは, 分子量約 20 万の $\mathrm{iPP}$ に対して, 分子量約 100 万の超高分 子量 iPPを添加した試料を複数の添加濃度で用意し, せ 几断誘起結晶化過程における複屈折・濁度变化の測定を 行った，すると，ある臨界濃度以上の超高分子量成分を添 加すると, 射出成形体中のシシケバブ形成が、急激に加速し た．その超高分子量成分の臨界添加濃度は, de Gennesに よって提起された, 溶液中で超高分子量成分のランダムコ イル鎖が互いに重なり合い始める臨界濃度 $\left(c^{*}\right)$ とほぼ同 等であったことから, 高分子量成分同士が溶融状態で互い に重なり合い始めると,協同的にネットワークを形成して シシケバブ構造形成を促進するのだ，という考え方が受け 入れられるようになってきた.15.161

\section{2 シシケバブ構造における各分子量成分の存在状態の 解明 (中性子散乱実験)}

\subsection{1 実験の目的}

これまでの検討で, 超高分子量成分がある一定量以上添 加されないとシシケバブ形成が活性化されないこと, せん 断速度の臨界伹があることなどの知見から, 多くの研究者 は, シシケバブのシシ部分は, コイルーストレッチ転移し
た超高分子量成分が凝集して形成すると考えるようにな ってきた，そこで筆者らは，重水素でラべルされた高分子 を用いた中性子散乱法を駆使することによって, シシの構 成成分が, 実際に超高分子量だけから形成されているのか を確認する実験を行った.4.177

\subsection{2 実験法}

わ机われはまず, 分子量 150 万程度の (超) 高分子量成 分, 分子量 20 万程度の中分子量成分, 分子量 3 万程度の 低分子量成分の $\mathrm{iPP}$ の D 体と $\mathrm{H}$ 体を重合した. 中性子散乱 用試料として, $\mathrm{H}$ 体 $6 \mathrm{~g}$ に対して高分子量, 中分子量, 低 分子量のいずれかの D体を $1 \mathrm{~g}$ ブレンドし, 各分子量成 分をラベルした試料を得た. 高分子量成分を $1 \mathrm{~g}$ ラベル した試料をLong-D, 同様に中分子量成分をラベルした試 料を Medium-D, 低分子量をラベルしたものを Short-D と 呼ぶことにする.いず机の試料も, 高分子量：中分子量： 低分子量 $=2: 4: 1$ の比率で, 各分子量成分のポリマー をブレンドしている. (各試料の構造は表 1 を参照)。混合 は熱キシレン溶液で混合し, 再沈回収して混合ブレンドを 得たＤ体ポリマーと $\mathrm{H}$ 体ポリマーを混合すると高分子 の種類によっては相分離を誘発するが, iPPでは, 分子量 150 万でも D 体と H 体が相溶することが知られており, 本 検討の試料でも初期状態は完全に混合した状態であるこ とが,われわれの実験で測定した中性子散乱のプロファイ ルからも確認されている.

こ机らのD体ラベル試料をカリフォルニア工科大学の Kornfield 教授が開発した小型射出成形機181 で成形する ことで, シシケバブ構造を有する成形体を得た(図3)。成

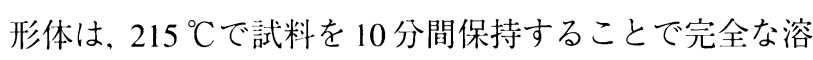
融状態とした後, $190^{\circ} \mathrm{C}$ に保持された金型に約 $0.7 \mathrm{MPa}$ の 射出圧で樹脂を流し込み, その後金型温度を $140{ }^{\circ} \mathrm{C}$ まで冷 却して等温結晶化させて加工した.この実験で最も重要な ことの 1 つは, D 体ラベルすることが成形体の構造形成 · 最終的な形態に影響を与えないことである. 成形体の構造 形成に関しては，その過程を複屈折・濁度の变化でモニタ リングし,いずれの試料も同等の構造形成過程を経ている

表1 各重水素含有試料および, 試料内に含まれる重水 素置換した成分の重量平均分子量と分子量分布. (Weight-average molecular weight mass $\left(M_{\mathrm{w}}\right)$ and polydispersity $\left(M_{\mathrm{w}} / M_{\mathrm{n}}\right)$ of the deuteriumlabeled fraction and of the blend as a whole. Each blend contains 13 weight \% labeled chains.)

\begin{tabular}{lcclcc} 
& \multicolumn{2}{c}{$\begin{array}{c}\text { Deuterium-labeled } \\
\text { species }\end{array}$} & & \multicolumn{2}{c}{ Blend } \\
\cline { 2 - 3 } \cline { 6 - 6 } & $\begin{array}{c}M_{\mathrm{w}} \\
\mathrm{kg} / \mathrm{mol})\end{array}$ & $M_{\mathrm{w}} / M_{\mathrm{n}}$ & & $\begin{array}{c}M_{\mathrm{w}} \\
(\mathrm{kg} / \mathrm{mol})\end{array}$ & $M_{\mathrm{w}} / M_{\mathrm{n}}$ \\
\hline Short-D & 41 & 2.4 & & 467 & 8.3 \\
Medium-D & 197 & 3.2 & & 486 & 7.9 \\
Long-D & 1781 & 3.1 & & 557 & 8.6 \\
\hline
\end{tabular}



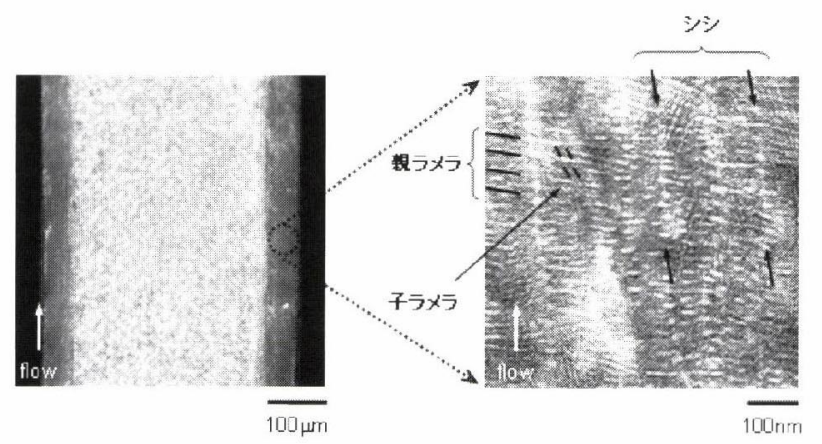

図3 成形試料断面の偏光顕微鏡像 (左) と, せん断層部 分の透過電子顕微鏡 (TEM) 像 (右). TEM 像から はシシケバブ構造を明確に観察できる。いずれの 成形試料でも, 同等の構造が観察された。((left) Polarized optical microscope image of cross section of a molded sample under pulsed shear. (right) TEM picture of sheared layer in the molded sample. Shishkebab morphology is clearly observed. In any of three deuterated samples, similar morphology was observed.)

ことを確認している、さらに, 成形体の最終形態(結晶構 造)が同等であるかを確認するために, 成形後の各サンプ ルのSAXS - WAXS 測定を行った. その結果, ミクロンス ケールからナノスケールまでの広い階層構造の範囲で Long, Medium, Short-Dのいずれの試料もほとんど完全 に同じモルフォロジーを有していることが確認された。

\section{2 .3 実験結果と考察}

Long, Medium, Short-Dの 3 種類のD化ラベル成形体に ついて, まず室温で中性子小角散乱測定を行った。その結 果を図4の左列に示す. 中性子散乱以外の方法ではモル フォロジーに違いが見えなかったにもかかわらず, 試料 間でまったく異なった中性子の散乱パターンを示している. このことは, シシケバブ構造中における各分子量成分の 存在状態の違いを明確に示している. Short-D, Medium-D については，流動方向 (上下方向) に沿って垂直方向に 強く配向した散乱パターンのほかに, 流動方向に直交す る水平方向にも強い散乱が現れているが, Long-Dでは 水平方向の散乱はほとんど観察されない. 垂直方向に現れ る散乱パターンはケバブとして存在するラメラ構造の周 期に関連する散乱であると考えられるが，水平方向の散 乱は, 一般的に変形した分子の異方性か, 流動と直交する 方向における各成分の濃度の粗密を表すと考えられる. しかし, 室温ではケバブを形成しているラメラ結晶から の散乱の寄与を含み, ポリプロピレンはシシに引き続き 成長する初期のケバブであるラメラ晶 (親ラメラ) からほ ぼ垂直に二次的にエピタキシャル成長するラメラ晶 (子ラ メラ）も存在すると予想されるため, 必ずしも明確な議論 ができない，そこで成形試料を加熱し，シシケバブの融解 過程における中性子散乱パターンの変化を測定すること

日本結晶学会誌 第 50 巻 第 4 号 (2008)

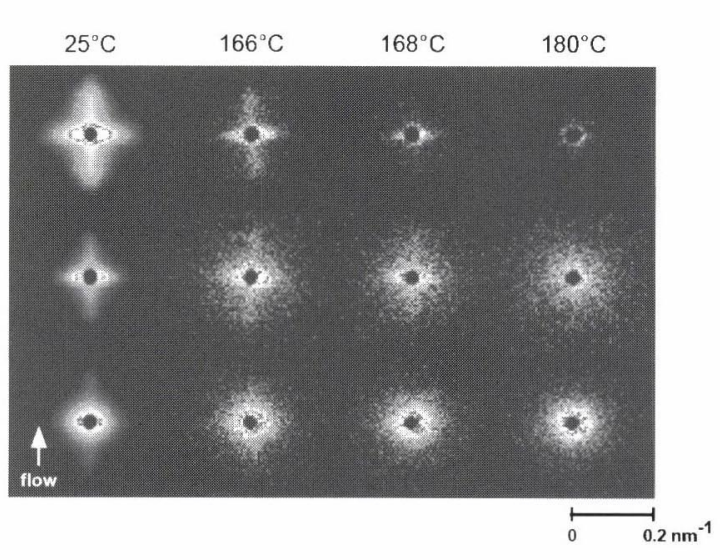

図 4 Short-D (上段), Medium-D (中段), Long-D (下段) について, 室温から昇温していったときの中性子 散乱像の変化. ${ }^{19)}$ (The changes of SANS patterns during heating in Short-D (upper), Medium-D (middle) and Long-D (bottom).)

で：シシケバブの形成過程を推測することにした，加熱は $2{ }^{\circ} \mathrm{C} / \min$ で行い, 中性子の露光は 1 分間ずつ行った. その 結果をまとめたものを図4の右四に示す．加熱によりケバ ブが融解していく様子が観察できる，一方で，水平方向 の散乱については, ケバブ融解後にも, 弱いながらも Short-D と Medium-Dの両試料で観察されている. 水平 方向の散乱の存在をより明確に確認するため, ケバブ融 解時の散乱パターシから $180{ }^{\circ} \mathrm{C} て ゙$ 完全に融解したデータ を引き算する処理を行った（図 5)。図 5 より, Short-D, Medium-D では明らかに水平方向にストリーク状散乱が見 えるが, Long-Dでは明確な異方性がやはり観察されない. このことは, 高分子量成分は, シシ領域でもシシ以外の 領域でも同じ濃度で存在することを強く示唆している. もしも, 超高分子量成分がコイルーストレッチ転移して凝 集してシシを形成するならば, 超高分子量成分をD化した Long-D で水平方向に強い異方性をもったストリーク状の 散乱が観察されるはずである。一方, Medium-D, Short-D で 観察される異方性の散乱は, どちらかの成分がシシに多 く，もう片方の成分がシシに少なく含まれているか，もし くはシシ構造内部において不均一な分布を形成している ことを示唆している.

この実験結果は, これまで考えられていた超高分子量が シシとなっている，とする説を完全に覆すものである. 確 かに, 超高分子量成分が存在することによってシシ形成は 促進するが，せん断下では分子は大きく伸長できず，限ら れた幾何学的な制約の中で分子の一部が局所的な伸張を することしかできず, 超高分子量成分が局所的な伸張変形 を起こす際に，ほかの分子量成分を取り达んでシシを形成 していると考えるのが自然であろうと思われる。ちなみ に, 超高分子量成分の拡散速度を考えると, 超高分子量が 凝集するイメージにいかに無理があるかがわかる、シシは 


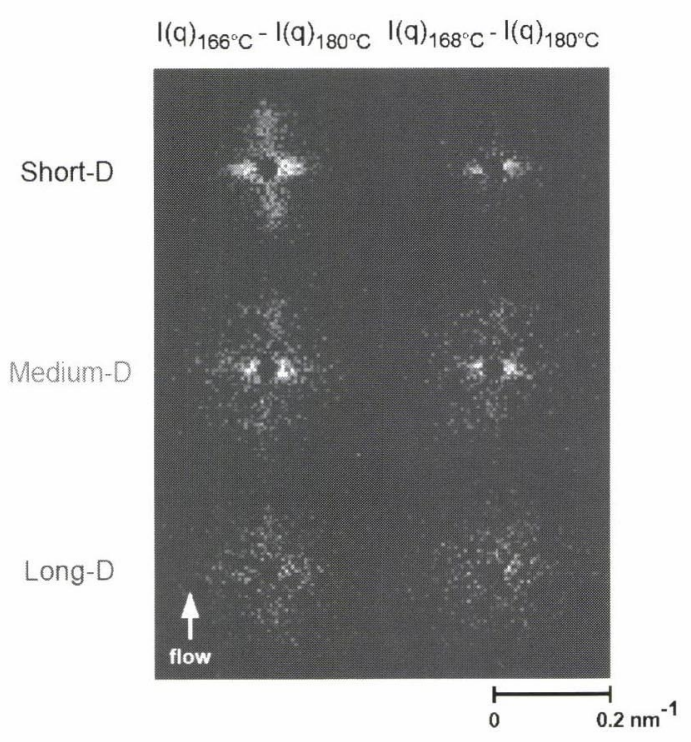

図 $5166{ }^{\circ} \mathrm{C}, 168{ }^{\circ} \mathrm{C}$ において観察された散乱パターンか ら溶融状態の $180{ }^{\circ} \mathrm{C}$ 散乱パターンを引き算した 差分の散乱パターン. ${ }^{19)}$ Short-D (上段), Medium-D (中段)においてストリーク状の散乱が観察される が, Long-D (下段)においては明確な異方性は観 察されない. (The change in SANS scattering intensity between $166^{\circ}$ and $180^{\circ} \mathrm{C}$ (left) and between $168^{\circ}$ and $180^{\circ} \mathrm{C}$ (right) for each of the three deuterium-labeled blends, Short-D (upper), MediumD (middle) and Long-D (bottom).)

1 秒で数 $\mu \mathrm{m}$ 程度成長することが知られている19) が, 分 子量 20 万の成分ですら, 1 秒間では $1 \mathrm{~nm}$ 程度しか拡散で きない.20)シシ形成のもとになるコイルーストレッチ転移 が, 緩和が長い1つの分子が大きく伸長する形で起こるの ではなく, 最も応力集中する絡み合い点(ないしは小さな 結晶前駆体のようなもの)の間で部分的な転移が起きて, 連結し成長するだろう, というのが今回の実験結果から得 られる結論である。

\section{3. 加熱延伸下での結晶変形挙動に関する研究}

\section{1 加熱延伸下での結晶変形に関するこれまでの研究}

延伸による結晶変形に関する研究について, 変形の初期 過程・後期過程に分けて, これまでに進められてきた研究 で明らかになってきた部分, 今もなお議論になっている部 分について簡単に説明する.

変形初期における, 球晶の変形状態については, 低い延 伸倍率で小変形した球晶を光学顥微鏡や電子顕微鏡によ り観察する方法で, 研究されてきた. Shimamuraらは, PE の球晶を冷延伸 (室温) · 熱延伸 $\left(100^{\circ} \mathrm{C}\right)$ したときに, 球晶 組織の中で, 先に変形する領域が異なることを見出した.21) 冷延伸では, 球晶のうち, ラメラの面法線が延伸と垂直に なっている構造部分から変形に起こっているのに対し, 熱 延伸では, 球晶のうち, ラメラの面法線が延伸と平行にな
っている構造部分から変形することが示された. 一方, 変 形初期におけるラメラ結晶レベルでの構造変化に関する 検討については, X線や中性子を用いた通常の散乱法など では, 球晶の全領域の構造変形を平均した情報しか得られ ないため, 有効な実験がほとんどされてこなかった。

変形後期に形成する変形構造に関しては, 例えばX線, 中性了散乱, 電子顕微鏡などで観察する方法で盛んに検討 されていた，大変形後の $\mathrm{PE}$ 試料の電子顕微鏡観察から， 延伸によって十分変形した状態では, 結晶のラメラ面がジ グザグになっており, 結晶のサイズがかなり小さくなって いることがわかった.22) また，延伸大変形㖟のPE 試料を SAXS 測定すると, two bar pattern と言われる, 配向してい るバー状の散乱スポットが観察される.23).24)バー状の散 乱スポットは, まさにラメラ面がジグザグになっているこ とを強く示唆する. 変形初期に球晶の内部構造が変形・降 伏して配向した構造を形成した後に, 変形による結晶の微 細化がどのように起こるのかということはよく理解され ている。

しかし, 変形初期から降伏を経て配向構造を形成してい く過程で起こっている構造変化は, 時間分割 SAXS-WAXS 測定といった変形時の構造变化のその場観察などが進め られている25)(26)にもかかわらず, 先に述べたように，X 線から得られる構造情報が空間的に平均されてしまって いるという理由により詳細な理解が進んでおらず,多くの 謎に包まれている部分である，また，その謎の多い球晶の 降伏・配向過程で, 融解一再結晶化が起こっているとする 説もあり，その妥当性がSANS などの結果に基づいて議論 されている27,28)が,これもいまだに結論が出されておら ず, 熱い議論の対象になっている.

\section{2 球晶の局所領域における変形挙動の観察と応力伝搬 経路の解明 (マイクロビームX 線散乱) 5)}

\section{2 .1 実験の目的}

3.1 で紹介したように, 放射光X線散乱による球晶の延 伸变形過程その場観察では, 球晶のすべての領域で生じる 構造変形をす心゙て平均した散乱情報しか得ることができ ず，局所での変形過程を明らかにすることができなかっ た、そこで筆者らは, 統計的に信頼性があり, 十分に局所 での変形挙動を追跡することができる実験手法である,マ イクロビームX 線小角・広角散乱 ( $\mu$ SAXS-WAXS) 一偏光 顕微鏡司時観察法によって, 球晶中の一点における, 延伸 中に生じる階層構造変化のその場観察を行い, 変形の初期 に起こっているラメラ構造の変化を詳細に追跡した。

\section{2 .2 実験法}

球晶を延伸機で変形させると, 変形に伴い球晶の位置が ずれていくため, 延伸と独立に試料位置を調整する機構を もつ延伸機を設計した. また, 試料観察のための偏光顕微 鏡については, 延伸機中にセットされた試料が変形される 様子を明瞭に観察する必要があるため, 作動距離が $4 \mathrm{~cm}$ 
もある, 特別に作動距離が長い対物レンズを顕微鏡観察に 用いた。

試料は, iPP $\left(M_{\mathrm{w}}: 440,000, M_{\mathrm{w}} / M_{\mathrm{n}}: 4.8\right)$ を用いた。 融点は $160^{\circ} \mathrm{C}, \mathrm{NMR}$ から求められるペンタッド分率 (立体

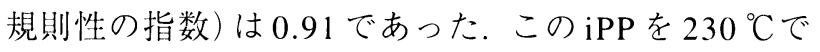
5 分融解して熱プレスした後, 結晶化温度 $128{ }^{\circ} \mathrm{Cに10〜}$ 12 時間保持して等温結晶化させ, 巨大球晶 (球晶直径：約 $200 ３ 00 \mu \mathrm{m}$ ）を作製した. 球晶の延伸は，上記延伸機を 用い, 延伸温度 $155^{\circ} \mathrm{C}$ で, 延伸速度 $0.05 \mathrm{~mm} / \mathrm{s}$ で延伸した。 延伸に伴って生じる高次構造の変化は, 散乱強度の弱い 構造秩序が低下した状態を経由するため, より輝度の高い SPring-8のX線源を用いた。 $\mu$ SAXS-WAXS 同時測定は BL40XUで行った. BL40XUは，ハッチ内（特に試料周り） の自由度が高い超高フラックスビームラインで, 波長の広 がりはあるものの, 非常に強度の強いX線を得ることが できる.マイクロビームの生成は, 直径 $2 \mu \mathrm{m}$ のピンホー ルと直径 $100 \mu \mathrm{m}$ のガードピンホールの対を, 試料の上流 側にセットすることで行った.このような非常に簡略なセ ットアップで, 試料位置でのビームサイズが $5 \times 5 \mu \mathrm{m}^{2}$ のマイクロビーム $(\mathrm{X}$ 線の波長：1 $\mathrm{A})$ が得られ, 最大 $1000 \AA$ 程度の構造を小角散乱で観察できた。検出器とし ては, 小角散乱測定にイメージインテンシファイア＋ $\mathrm{CCD}$ 型検出器29) を, 広角散乱測定にフラットパネル検出 器30)を用いた。

試料におけるマイクロビームの位置決めは, 以下の方法 を用いた．クロスした極細のワイヤ（直径 $20 \mu \mathrm{m}$ )を試料 に埋め込み, 試料中をマイクロビームで走査しながら散乱 パターンを観察しワイヤが交差した部分で観察されるこ とが期待されるX字型のダブルストリークが観察される 場所を見つけ，大体のビーム位置を決定した，その後，X 線を一定時間以上連続して試料に照射し, 試料を破壊して 穴を開けることで, 闹確なビーム位置を決定した。

\subsection{3実験結果・考察}

延伸前の球晶の局所にマイクロビームX線を照射して 得た $\mu S A X S-W A X S$ 像と光学顕微鏡像を図 6 に示す. $\mu S A X S$ は親ラメラの長周期に起因する散乱と親ラメラか らエピタキシャル成長して形成した子ラメラの長周期に

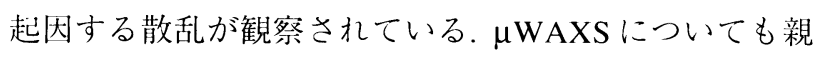
ラメラ・子ラメラの両方からの散乱が観察されている.こ れらの観測された散乱をまず的確に対応づける必要があ るが, 図7に示すようにラメラ面の法線が延伸方们に半行 な親ラメラ (以下, 平行親ラメラと呼ぶ) と垂直な親ラメ ラ (以下, 垂淔親ラメラと呼ぶ)，およびそ机らからエピ夕 キシャル成長した子ラメラを考えることで, 散乱の起源を すべて対応づけることができる. 対応づけされたそれぞれ の散乱が，変形中にどのように変化するかを追跡できれ ば, 変形時の各構造の変化の仕方を明確に理解できる.

まず, SAXS から得られる情報である, ラメラの長周期

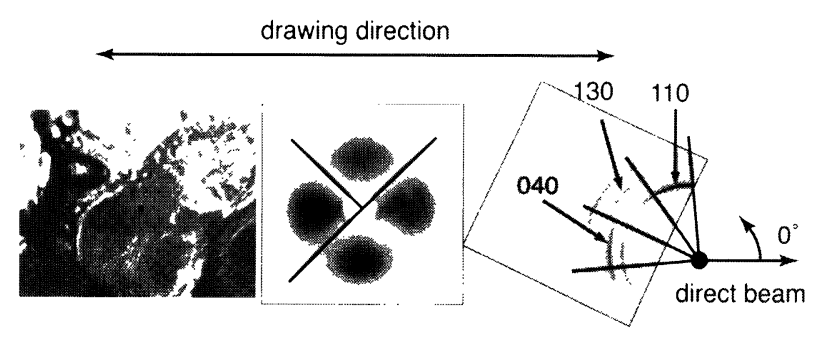

(a)

(b)

(c)

図6 変形前の球晶にマイクロビームを照射したとき (偏光顕微鏡 (a) の黑丸で示した部分) のSAXS (b), WAXS (c) データ. SAXS, WAXS について黑線で 示された領域ごとにセクターアベレージしてプロ ファイル解析を行った. (Typical dataset of POM (a), SAXS (b), and WAXS (c). In SAXS and WAXS, the boundary solid lines for sector average analyses are shown. In POM image, the position of the microbeam is shown as a dot. Definition of azimuthal angle is shown in (c).)

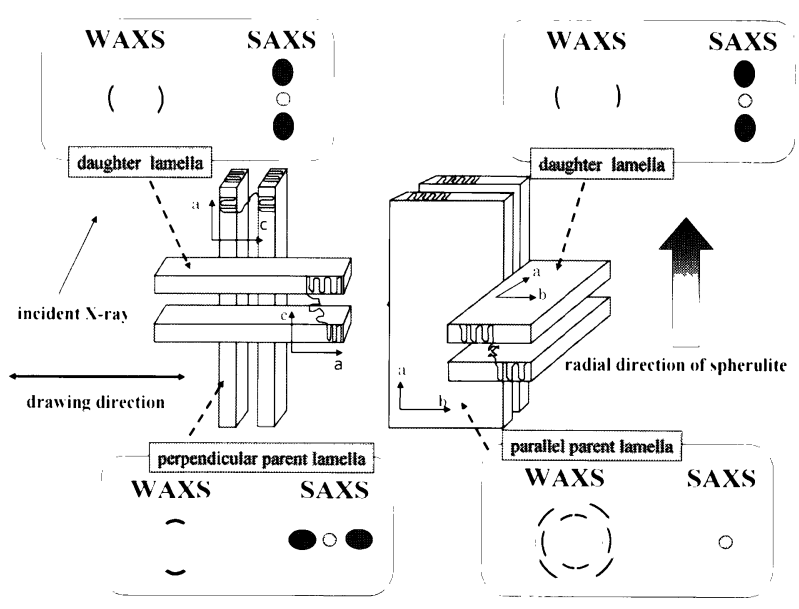

図 7 (延伸方向に対して面法線が) 半行な親ラメラ, 垂 直な親ラメラとそこから成長した子ラメラのイラ ストとそれらの構造に対応する SAXS - WAXS パ ターン. (Illustration of perpendicular and parallel parent lamellae and their daughter lamellae. The corresponding SAXS and WAXS are also shown.)

とその秩序性について解析したものを図8に示す。ここで は平行親ラメラと, 子ラメラについて解析している. 平行 親ラメラは, 延伸の初期で長周期が増加し, 半值幅も広が っていく.しかし, 横軸の 10 フレーム目近傍を境に, 長周 期が減少に転じ，半值幅も狭くなっていく．つまり，変形 初期には, 平行ラメラのラメラ面閒隔は広がり, かつ秩序 が低下するが、ある夕イミングを境にラメラ構造が降伏 し, ラメラ面の再構築が始まり秩序化が進行することを示 唆する. 一方, 千ラメラの長周期は, 延伸初期では長周期 とその秩序は変化せず, 親ラメラの降伏とほぼ同時に長周 期の減少と秩序の低下が生じ, 最終的には検出できなくな 


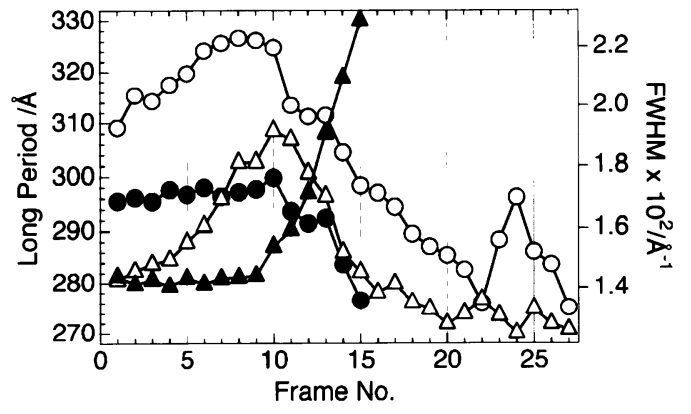

図8セクター平均したSAXS から得られた, 延伸変形 時の親ラメラと子ラメラの長周期と半值幅の変化. (○）親ラメラの長周期, (○) 子ラメラの長周期, $(\triangle)$ 親ラメラの半值幅, ( $\boldsymbol{\Delta})$ 子ラメラの半值幅. (Changes of long period and FWHM in parent and daughter lamellae obtained from the sector averaged SAXS profiles of iPP. (O) long periods of parent lamellae, (O) long periods of daughter lamellae, $(\triangle)$ FWHM of parent lamellae, ( $\Delta$ ) FWHM of daughter lamellae.)

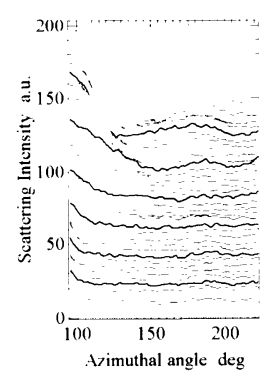

(a)

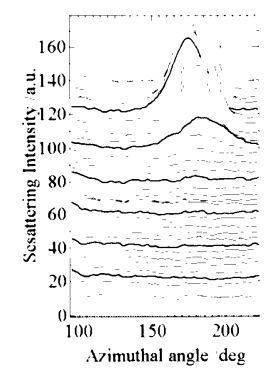

(b)

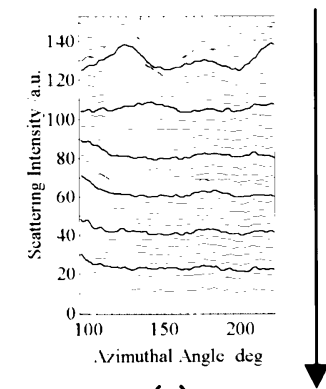

(c)
図9延伸変形時の 110 (a), 040 (b), 130 (c) の各反射の 方位角分布の変化を示した鳥瞰図. 5フレームご とに太線で示している. 矢印は時間の進行方向を 表す. (Bird's eye view of change of azimuthal distribution in (a) 110, (b) 040 and (c) 130 reflections of iPP. At every 5 frames, profiles are shown with a bold line. Arrows represent the time course.)

る.つまり，延伸初期には，子ラメラの長周期における变 化はほとんど起こっていないが, 親ラメラの降伏に伴って 劇的に秩序が低下し最終的に構造が消滅する。

次に $\mu \mathrm{WAXS}$ デー夕を解析する. 図 9 に, 延伸時の 110 , 040，130反射の方位角分布変化を示す，すべての反射は 延伸後, 最終的に方位角 $90^{\circ}$ 近傍に現机るようになるが, 図 9 を見ると, 各反射が $90^{\circ}$ 近傍に再配列するタイミング に時間差があることがわかる.再配列のタイミングは方位 角 $180^{\circ}$ 近傍に存在していた 110 反射 (平行親ラメラから 成長した子ラメラに帰属される反射) $130^{\circ}$ 近傍に存在し ていた 130 反射 (垂直親ラメラに帰属される反射), $180^{\circ}$ 近 傍に存在していた 040 反射 (垂直親ラメラから成長した子

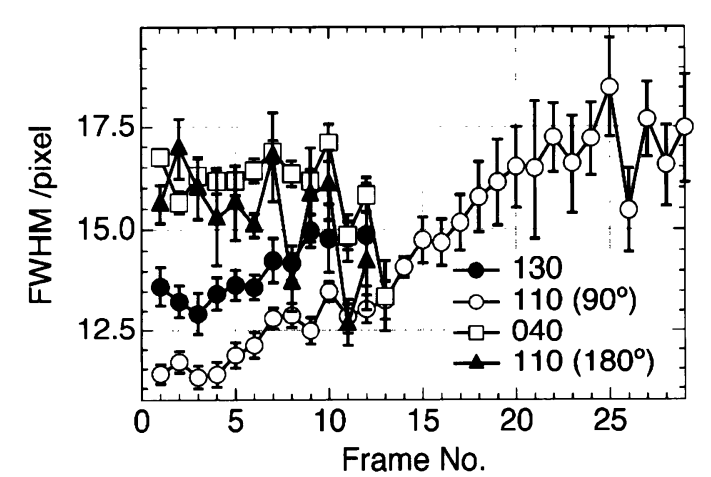

図 10 延伸変形中の $110,040,130$ の各反射の半值幅の変 化. 110 反射については方位角 $90^{\circ}$ に現れる平行 及び垂直親ラメラに起因する散乱と, $180^{\circ}$ に現れ る平行親ラメラから成長した子ラメラに起因する 散乱について解析を行った. (Changes of FWHM of 110,040 and 130 reflection of iPP during hot drawing. With respect to 110 reflection, both reflections at $90^{\circ}$ (corresponding perpendicular and parallel parent lamellae) and $180^{\circ}$ (corresponding daughter lamellae of parallel parent lamellae) were analyzed.)

ラメラに帰属される反射) の順番になっていることがわか る. また, WAXS の動径方向へのプロファイルから半值 幅の変化を求めた (図 10)。すると, 子ラメラの結晶サイ ズ (ないしは秩序の度合い) は親ラメラの結晶サイズと比 べて最初から小さくなっているが, 延伸の初期では親ラメ ラの結晶サイズの低下 (ないしは低秩序化) が起こるのに 対し. 子ラメラの結晶サイズはほとんど変わっていないこ とがわかる。

上記の $\mu S A X S-W A X S$ デー夕解析を組み合わせると次 のような経路で変形が起こっていることがわかる.

(1)延伸変形の最初期に平行親ラメラの結晶間が（おそらく 非晶の伸長により)延ばされる.

(2)延伸初期から降伏までは親ラメラの積層構造・パッキ ング構造の両方の秩序低下が優先的に進み, 子ラメラの 構造に対してはほとんど延伸の影響を受けていない。

(3)ラメラの低秩序化がある一定以上進んだところで, (降 伏が起こって) ラメラ面の再配列が起こる. 再配列の順 序は，延伸に平行な向きの親ラメラとその子ラメラ，そ の後延伸に垂直な问きの親ラメラ・子ラメラの順序に なっている.

このようにして, 球晶の局所に扔ける変形の過程を非常 に詳細に調べることができた，言い換えると，この構造変 形の序列は, 㐫力がどのように伝播して構造が破壊されて いくかを明確に示している. $\mu$ SAXS-WAXS を用いるこ とで初めて, 延伸による広い階層レベルでの構造変化を, ごくわずかな構造变化 (結晶秩序の変化や特定の成分の長 周期とその秩序の変化など) のレベルで詳細に捕えること ができる、ということを示すことができたと考えている. 


\section{4. まとめ}

成形加工の実場面で高分子に印加されているせん断や 延伸などの外場は，高分子の高次構造の形成に非常に複 雑な影響を与えている。成形加工時に起こっている一連 の複雑な構造形成過程の理解なくして, 高性能材料の設 計・開発が成り立たないのは，当然のことである。本稿で 紹介した, マイクロビームX線散乱や, 重水素ラベル技 術を駆使した中性子散乱に代表される散乱手法は, 謎め いた部分の多い外場下での構造形成過程に光を照らす, 非 常に有効な手法となり得る。これからも, より一層, 高分 子成形加工の本質を掴み取るような散乱研究を積極的に 進めていきたいと考えている.

\section{謝 辞}

本研究を進めるにあたり, 数多くの方のご指導を賜 った。学生 (学部・修士・博士) 時代の恩師である雨宮慶 幸教授 (東京大学・新領域) には, 言葉では尽くせ奴 どの温かいご指導をいただいた，また，マイクロビームX 線散乱実験では, 飯田厚夫教授 $(\mathrm{KEK} \cdot \mathrm{PF})$, 八木直人主 任研究員 (JASRI - SPring-8), 篠原佑也助教 (東京大学 · 新領域)をはじめとする多くの方々のご指導・ご協力をい ただいた，中性子散乱においては，松下裕秀教授 (名古屋 大学・工学研究科) のご指導の下で中性子散乱実験の基礎 を学ばせていただき, 本中性子散乱実験では柴山充弘教 授 (東京大学・物性研) の厚いご協力をいただいた。また， 山口登主席研究員をはじめとする, 住友化学(侏における上 司・同僚の温かい励まし・指導・協力があって, 一連の仕 事をまとめることができた。ここに, 厚くお礼申し上げる.

\section{文 献}

1) A. J. Pennings, A. M. Kiel: Kolloid Z. Z. Polym. 205, 160 (1965).

2) H. D. Keith and F. J. Padden, Jr.: J. Appl. Phys. 37, 4013 (1996).

3) A. Keller: J. Polym. Sci., 17, 291 (1955).

4) S. Kimata, T. Sakurai, Y. Nozue, T. Kasahara, N. Yamaguchi, T. Karino, M. Shibayama and J. A. Kornfield: Science, 316, 1014 (2007).

5) Y. Nozue, Y. Shinohara, Y. Ogawa, T. Sakurai, H. Hori, T. Kasahara, N. Yamaguchi, N. Yagi and Y. Amemiya: Macromolecules, 40, 2036 (2007).

6) S. Mitsuhashi: Bull. Text. Res. Inst. 66, 1 (1963).

7) Z. Bashir, J. A. Odell and A. Keller: J. Mater. Sci. 19, 3713 (1984).

8) Z. Bashir, J. A. Odell and A. Keller: J. Mater. Sci. 21, 3993 (1986).

9) J. A. Odell, D. T. Grubb and A. Keller: Polymer 19, 617 (1978).
10) http://www.toyobo.co.jp/seihin/dn/dyneema/

11) P. G. de Gennes: in Scaling Concept in Polymer Pyhsics.

12) P. Jeschow and H. Janeschitz-Kriegl: Rheol. Acta 35, 127 (1996).

13) S. Liedauer, G. Eder, H. Janeschitz-Kriegl, P. Jerschow, W. Geymayer and E. Ingolic: Intern. Polymer Processing 3, 236 (1993).

14) M. Seki, D. W. Thurman, J. P. Oberhauser and J. A. Kornfield: Macromolecules 35, 2583 (2002).

15) E. L. Heeley, C. M. Fernyhough, R. S. Graham, P. D. Olmsted, N. J. Inkson, J. Embery, D. J. Groves, T. C. B. McLeish, A. C. Meneau, W. Bras and A. J. Ryan: Macromolecules 39, 5058 (2006).

16) G. Matsuba, S. Sakamoto, Y. Ogino, K. Nishida and T. Kanaya: Macromolecules 40, 3650 (2007).

17）文献4) のわれわれの研究は, 住友化学株とカリフォルニア工科 大学の J.A.Kornfield 教授, 東京大学物性研究所の柴山充弘教授の グループとの共同研究である.

18) G. Kumaraswamy, R. K. Verma and J. A. Kornfield: Rev. Sci. Instrum. 70, 2097 (1999).

19) J. A. Kornfield, G. Kumaraswamy and A. M. Issaian: Ind. Eng. Chem. Res. 41, 6383 (2002).

20) J. van Meerveld: Rheol. Acta 43, 615 (2004).

21) K. Shimamura, S. Murakami, M. Tsuji and K. Katayama: Nihon Rheol. Gakkai-shi 7, 42 (1979).

22) W. W. Adams, D. Yang and E. L. Thomas: J. Mater. Sci. 21, 2239 (1986).

23) N. S. Murthy, C. Bendarczyk, R. A. F. Moore and D. T. Grubb: J. Polym. Sci. Part B Polym. Phys. 34, 821 (1996).

24) Y. Tang, Z. Jiang, Y. Men, L. An, H. F. Enderle, D. Lilge, S. V. Roth and R. Gehrke: J. Rieger Polymer 48, 5125 (2007).

25) M. F. Butler and A. M. Donald: A. J. Ryan Polymer, 39, 39 (1998).

26) T. Sakurai, Y. Nozue, T. Kasahara, K. Mizunuma, N. Yamaguchi, K. Tashiro and Y. Amemiya: Polymer 46, 8846 (2005).

27) G. D. Wignall and W. Wu: Polym. Commun. 54, 354 (1983).

28) D. M. Sadler and P. J. Barham: Polymer 31, 36 (1990).

29) Y. Amemiya, K. Ito, N. Yagi, Y. Asano, K. Wakabayashi and T. Ueki: Rev. Sci. Instrum. 66, 2290 (1995).

30) N. Yagi and K. Inoue: J. Appl. Cryst. 40, s439 (2007).

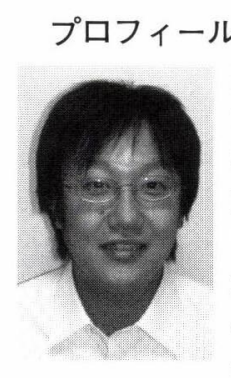

野末佳伸 Yoshinobu NOZUE 住友化学:株不油化学品研究所

Sumitomo Chemical Co., Ltd., Petrochemicals Research Laboratory 于 299-0295 住所千葉県袖个浦市北袖 2-1

2-1 Kitasode, Sodegaura City, Chiba 299-0295, Japan e-mail: nozue@sc.sumitomo-chem.co.jp 最終学歴: 東京大学工学系研究科物理工学専攻博 士後期課程修了

専門分野：X線·中性子散乱，高分子物理 現在の研究テーマ:ポリオレフィンの開発研究 趣味：バドミントン・卓球・散乱実験 